
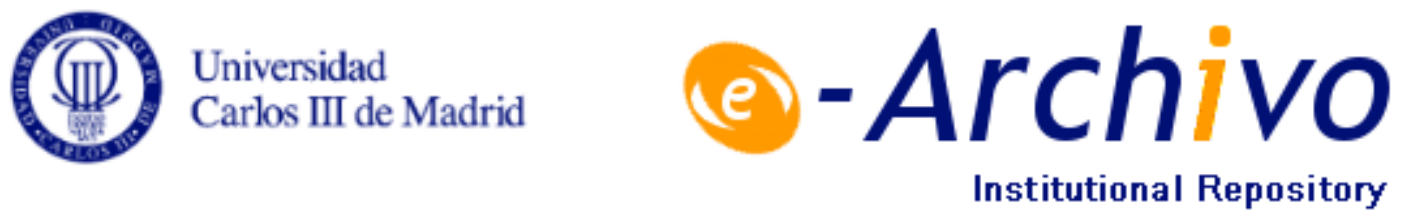

This is a postprint version of the following published document:

Marques, H., Pino, G. y Tena Horrillo, J. D. (2014). Regional inflation dynamics using space-time models. Empirical Economics, v. 47, n. 3, pp. 1147-1172. Avalaible in: http://dx.doi.org/10.1007/s00181-013-0763-9

C Springer 


\title{
Regional inflation dynamics using space-time models
}

\author{
Helena Marques • Gabriel Pino • \\ Juan de Dios Tena Horrillo
}

\begin{abstract}
This article provides empirical evidence of the role of spatial factors on the determination of inflation dynamics for a representative set of tradable commodities in Chile. We present a simple model that explains inflation divergence across regions in a monetary union with similar preferences as a consequence of the geographical allocation of producers in the different regions. Our results indicate that spatial allocation together with transport costs are important determinants of regional inflation, while macroeconomic common factors do not play an important role in this process. Existing literature had obtained the opposite result for Europe, and the reasons for this difference warrant further investigation. Moreover, we find that geographical distance seems to be a more appropriate measure of neighbourhood than the adjacency of regions. Our results are robust to different specifications, regression methods and product groupings.
\end{abstract}

\footnotetext{
H. Marques

Department of Applied Economics, University of the Balearic Islands, Edifici Gaspar Melchor de Jovellanos, Cra. de Valldemossa km. 7.5, 07122 Palma de Mallorca, Spain

e-mail: helena.ferreira-marques@uib.es

G. Pino

Department of Economics, Universidad Católica del Norte, Avenida Angamos 0610, Antofagasta, Chile

e-mail: gpino02@ucn.cl

J. de Dios Tena Horrillo ( $\square)$

DiSEA and CRENoS, Università di Sassari, Via Torre Tonda, 34, 07100 Sassari, Italy

e-mail: jtena@est-econ.uc3m

J. de Dios Tena Horrillo

Department of Statistics, Universidad Carlos III de madrid, C/Madrid, 126,

28903 Getafe, Madrid, Spain
} 
Keywords Regional inflation dynamics - Space-time models · Common factors . Chile

JEL Classification $\quad \mathrm{E} 31 \cdot \mathrm{E} 52 \cdot \mathrm{E} 58 \cdot \mathrm{R} 11 \cdot \mathrm{C} 23 \cdot \mathrm{C} 21$

\section{Introduction}

Explaining persistent inflation differentials across the various geographical areas that make up a monetary union has been a recurrent topic in the economics literature. Two recent and important contributions in this field are Altissimo et al. (2005), who present a theoretical model to explain inflation dispersion in the non-traded sector, and Andrés et al. (2008) who focus on tradable goods, suggesting that inflation differentials may be substantial over the business cycle mainly because of different preferences of individuals in different countries.

In this article, we show that another factor-transport costs—can explain persistent inflation differentials for tradable goods even when individual preferences in the different regions are identical. This intuition is motivated with a simple modified version of the Obstfeld and Rogoff (1995) model (O\&R henceforth) for two different regions in a monetary union. Unlike $O \& R$, in our model, exchange rates are fixed and do not adjust to fulfill the law of one price. Instead, under sticky prices and in the presence of transport costs, the proportion of producers in the two regions can explain the asymmetric reactions of regional prices and incomes to the same type of macro shocks and thus explain persistent inflation divergence across the monetary union. However, the distribution of producers matters because of the existence of transport costs. Without transport costs, any local shock would propagate immediately to the whole country due to arbitrage, and regional price differentials would not be sustainable.

The role of spatial factors in the determination of inflation dynamics is tested for a representative set of 98 tradable commodity prices of which have been taken monthly for 23 cities of Chile for the period 2003:01-2006:09. Chile has an unusual ribbon-like shape which is on average $175 \mathrm{~km}$ wide and 4,300 km long. This length is higher than, for example, the distance from Madrid to Moscow $(3,438 \mathrm{~km})$. Due to its natural geography and climate that prevent perfect price arbitrage, the Chilean case allows a natural application of spatial econometric models to the explanation of the heterogeneity of inflation dynamics at the regional and product level. Indeed, our objective in this article is to identify the existence of spatial correlation in regional prices rather than to predict the dynamic evolution of prices.

This article introduces two important novel features with respect to previous studies that tested spatial price homogeneity (law of one price), such as Parsley and Wei (1996) and Cecchetti et al. (2002) for the US, or Beck et al. (2009) for the Euro Area. First, as far as we are aware, ours is the first attempt to investigate the heterogeneity of inflation dynamics for an emerging market with such a level of detail. Indeed, we explore the product and geographical dimensions of Chilean inflation using spatial econometric models. The second aspect relates to our study of inflation dispersion for individual prices and not for price indices. This is an important issue given that a price index could evolve differently across regions just because of different weights in the 
representative basket of consumption. The individual consideration of homogeneous product categories eliminates this problem.

Our results indicate an important degree of spatial correlation in the determination of commodity prices, supporting the theoretical result that persistent inflation differences across space can be due to the geographical allocation of producers. Also, in contrast to what Beck et al. (2009) have found for the Euro Area, in Chile, common macroeconomic factors only explain a small proportion of the variability of inflation for the different commodities. These results are robust to a series of experiments controlling for endogeneity, non-stationarity, location-specific inflation dynamics, independence of markets and product grouping, and alternative measures of distance.

The structure of this article is as follows. Section 2 proposes a simple model that explains regional divergence in the inflation rates through the role of transport costs. Section 3 presents the dataset used in the empirical analysis and explains some of its features. Section 4 discusses the benchmark empirical results, and Sect. 5 summarizes a range of alternative spatial econometric methods and model specifications estimated to check the robustness of our baseline results. Section 6 interprets the signs of the coefficients, and some concluding remarks follow in Sect. 7.

\section{Theoretical underpinnings}

The role of transport costs in determining inflation dynamics can be explained theoretically by a simplified version of the O\&R model for different regions in a single country. An important feature of this framework is that all goods are traded, but goods produced in a location different from their consumption location are subject to a transport cost. Unlike O\&R who focus their attention on the effect of monetary policy and the exchange rate adjustment to maintain the purchasing power parity between prices in two different countries, here we deal with regions inside the same country, and the relationships between prices in each region are governed by transport costs instead of exchange rates. Under the assumption of sticky prices, shocks to demand and transport costs can alter relative prices and generate asymmetrical reactions across regions, even if all individuals have the same preferences independently of their location.

We assume the world is inhabited by a continuum of individual monopolistic producers, indexed by $z \in[0,1]$, each of whom produces a single differentiated good, also indexed by $z .{ }^{1}$ All producers locate in one of two regions, central or peripheral.

\footnotetext{
1 We assume monopolistic competition given that it is realistic to think that most commodities are not perfect substitutes. This could be true even for similar commodities due, for example, to the required time to gather information about new alternative sellers or to some degree of differentiation as a consequence of advertising. This assumption also allows us to compare our framework to that of Obstfeld and Rogoff (1995) and to other relevant contributions in the field. Nevertheless, some of the commodities considered in the article are likely to be homogeneous across producers. If this is the case, then we would have a model a la Hotelling in which firms located in the centre of the market have more power to steal customers compared with its rivals. Under this assumption, it would be possible to observe different prices in different geographical areas, and this difference would be determined by transport costs. However, given the assumption of homogenous commodities in a perfectly competitive market, spatial prices would adjust immediately to exogenous shocks, and it should not be possible to observe persistent differences in the inflation dynamics of the different Chilean cities. As is shown further ahead, the empirical results of the article, by demonstrating
} 
Central regions produce in the interval $[0, n]$, whereas peripheral regions are located in $(n, 1]$. Each agent located in one of the regions produces a variety of one type of good, $y(z)$, in which that region is specialized. Irrespective of their location, all producers sell some of their production in the central market, $y_{C, t}(z)$, and the rest in the peripheral market, $y_{P, t}(z)=y(z)-y_{C, t}(z)$. Because each variety is unique, they enjoy some monopolistic power both at their home region and outside.

All individuals throughout the country have identical preferences over a consumption index, real money balances and effort expended in production, whether they locate in the central or in the peripheral region. The intertemporal utility function of a typical agent $\mathrm{j}$ is given by

$$
U_{t}^{j}=\sum_{s=t}^{\infty} \beta^{s-t}\left[\log C_{s}^{j}+\chi \log \frac{M_{s}^{j}}{P_{s}}-\frac{\kappa}{2} y_{s}(j)^{2}\right]
$$

The variable $C$ is a real consumption index

$$
C^{j}=\left[\int_{0}^{1} c^{j}(z)^{\frac{\theta-1}{\theta}} \mathrm{d} z\right]^{\frac{\theta}{\theta-1}}
$$

where $c^{j}(z)$ is the jth Home individual's consumption of good $z$, and $\theta>1$.

Let $p(z)$ be the Home-currency price of good $z$. Then, the Home money price index is

$$
P=\left[\int_{0}^{1} p(z)^{1-z} \mathrm{~d} z\right]^{\frac{1}{1-\theta}}
$$

The most important difference between this framework and the O\&R model is the derivation of the relationship between $P$ and $P^{*}$. Here, it is assumed that all goods can be traded, although in doing so, transport costs are incurred according to an iceberg transport technology (see Fujita et al. 1999). ${ }^{2}$ Then, if the transport cost of a good from one region to another is $\boldsymbol{T}_{\boldsymbol{t}}$, the relationship between the prices in the two regions is given by

$$
\begin{aligned}
& p(z) T_{t}=p^{*}(z) \text { if } \quad z \leq n \\
& p(z)=T_{t} p^{*}(z) \text { if } \quad z>n
\end{aligned}
$$

where $T_{t}>1$.

Footnote 1 Continued

the time-lagged adjustment of prices, provide evidence against the assumption of perfect competition and in favour of monopolistic competition.

2 The assumption that all goods can be traded precludes other effects inducing price divergence, such as the Balassa-Samuelson effect. In this way, we are left with transport costs and short run rigidities as the only sources of price divergence. Naturally, in the long run, all persistent divergence is attributable to transport costs. 
Now, we can write the central price index as

$$
P=\left[\int_{0}^{1} p(z)^{1-z} \mathrm{~d} z\right]^{\frac{1}{1-\theta}}=\left[\int_{0}^{n} p(z)^{1-\theta} \mathrm{d} z+\int_{n}^{1}\left[T_{t} p^{*}(z)\right]^{1-\theta} \mathrm{d} z\right]^{\frac{1}{1-\theta}}
$$

Similarly, the peripheral price index is

$$
P^{*}=\left[\int_{0}^{1} p^{*}(z)^{1-z} \mathrm{~d} z\right]^{\frac{1}{1-\theta}}=\left[\int_{0}^{n}\left[p(z) T_{t}\right]^{1-\theta} \mathrm{d} z+\int_{n}^{1} p^{*}(z)^{1-\theta} \mathrm{d} z\right]^{\frac{1}{1-\theta}}
$$

An important point to note is that, although all agents have similar preferences, the law of one price is not necessarily met. In general,

$$
P \neq P^{*}
$$

Prices in the central and peripheral regions will be different if the locations of agents in the two regions are asymmetrical. In this model, the proportion of individuals allocated to the different regions is considered exogenous as the location decision could be affected by geographical, political, economical and historical reasons. Hence, we can suppose that in general the allocation of producers will in fact be asymmetrical. As we show later, in this case, transport costs play a key role in perpetuating price dispersion.

Similar to O\&R, the only internationally traded asset is a riskless real bond denominated in the composite consumption good. The period budget constraint for a representative Home individual $\mathrm{j}$ can be written in nominal terms as

$$
P_{t} B_{t+1}^{j}+M_{t}=P_{t}\left(1+r_{t}\right) B_{t}^{j}+M_{t-1}+p_{t}(j) y_{t}(j)-P_{t} C_{t}^{j}
$$

where $r_{t}$ denotes the real interest rate on bonds between $t-1$ and $t, y_{t}(j)$ is output for good $j$ and $p_{t}(j)$ is the domestic currency price. The variable $M_{t-1}^{j}$ is agent $j^{\prime} s$ holdings of nominal money balances entering at period $t$.

The economy is a closed one, and we do not consider a foreign country as our interest lies in analysing the differences across regions in the same country. Therefore, a single monetary aggregate is considered for both regions. Under the assumption that the monetary authority runs a balanced budget at each period and given that, for simplicity, we do not consider taxes and government spending, the following condition must be verified:

$$
0=\frac{M_{t}-M_{t-1}}{P_{t}}
$$

The set of equilibrium conditions obtained by following a similar approach to O\&R is confined to Appendix 1. Given that prices are determined by monetary policy and both regions face the same type of monetary policy shocks, the only value of $\hat{t}_{t}$ that is consistent with similar prices in the central and peripheral areas is $\hat{t}_{t}=0$. However, it is far more interesting to study the case in which transport costs are altered and 
the adjustment of prices to the new level of transport costs takes place with a oneperiod time lag. Movements in transport costs could be explained either by a common demand shock that affects demand for all goods in the economy or by an international oil shock. In both cases, shocks at the national level will exert an asymmetrical effect in the two regions. To see this, notice that, under sticky producer prices, any change in transport costs would alter consumer prices in the central and peripheral areas in the following way:

$$
\begin{gathered}
\hat{p}=(1-n) \hat{t} \\
\hat{p}^{*}=n \hat{t}
\end{gathered}
$$

The first thing to note is that consumer price indexes in the central and peripheral regions will differ except when the two regions are of equal size $(n=0.5)$. Otherwise, differences in the general price index will be generated from the aggregation of different prices of individual commodities in different regions according to their location and associated transport cost. That is, for the aggregate price indices to differ it is necessary that at least one individual price differs. In particular, if $n>0.5$ the consumer price index after the shock will be higher in the peripheral region compared with the central region. This happens because individuals in the peripheral region have to pay for the cost of transporting all traded goods produced in the most-populated areas (the central region). The asymmetry in consumer price indices also has an asymmetrical effect on the level of consumption and income in the two areas, as given by the following equations:

$$
\begin{gathered}
\hat{y}-\hat{y}^{*}=\theta[-n \hat{t}+(1-n) \hat{t}] \\
\hat{y}-\hat{y}^{*}=-\frac{\theta}{1+\theta}\left(c-c^{*}\right)
\end{gathered}
$$

Therefore, a shock to transport costs alters the distribution of income in the two regions. Moreover, by subtracting the Euler Eqs. (2.12) and (2.13) in the central and peripheral regions, it can be seen that these relative changes in consumption levels are always permanent.

To sum up, it is clear from this model that the existence of transport costs together with nominal rigidities effectively prevents the elimination of regional inflation differentials as changes in transport costs will lead to persistent changes in relative consumer prices in the two regions that will last until nominal prices adjust to the new equilibrium. Accordingly, we should find in the empirical analysis that regional inflations in the short and medium runs are not only determined by monetary policy but also by transport costs. Testing this article theory for the case of Chile is the main task of the subsequent sections.

\section{Empirical considerations}

As explained in the previous section, in this article, the gap between consumer and producer prices is modelled as an iceberg transport cost. However, since transport costs are not directly observed, in the empirical study, we take them as a function 
of distance. In this way, the quantity being traded is like an iceberg that loses mass per unit of distance, or putting it the other way around, the price per unit traded goes up with each unit of distance. Hence, the iceberg transport cost is a function of the distance between consumption and production locations. This way of thinking about the iceberg transport cost was first proposed by Samuelson (1952), later used also by Helpman and Krugman (1985) and Krugman (1991), who thought of 'distance' as representing an index of spatial and non-spatial barriers to trade. In this article, we follow a strictly geographical interpretation of distance similar to that of Fujita and Krugman (1995) and Krugman (1995) and take the kilometric distance between locations (Chilean cities). ${ }^{3}$

For our analysis, we collected a panel of prices covering an important range of different types of foods and drinks as well as oil products, summing up to a total of 98 different products that are distributed across 12 groups of products with related characteristics. Price data were taken on a monthly basis in the period 2003:01-2006:09 for 23 cities that are representative of the 11 regions in Chile. Thus, we have a panel of 23 regions and 45 months. Given that our focus of interest is the annual inflation rate, we are able to run separate regressions for the 98 commodities keeping 759 observations in each regression. A list of the products, groups and cities considered is confined to Appendix 2.

The data are freely available from the National Statistical Institute of Chile ('Instituto Nacional de Estadística') at the URL http://www.ine.cl. This institution stopped publishing information on regional prices after September 2006, and so more recent data cannot be collected. However, even if this information had been available, inflation dynamics after that date followed a pattern that was not consistent with its equilibrium values and would represent an important break in the panel. More specifically, due to the higher increase in world food and oil prices since 2006, the average annual rate of Chilean inflation (i.e. the increase of the general index of consumer prices) was 7.8 and $7.1 \%$ in 2007 and 2008 respectively, while it had oscillated between 2 and $3 \%$ during the period 2004-2006.

Inflation rates for each of the items $\left(\pi_{t}\right)$ are computed as year-on-year percentage changes in the price index in the following way:

$$
\pi_{t}=100 *\left(\frac{P_{t}-P_{t-12}}{P_{t-12}}\right)
$$

where $P_{t}$ denotes the respective product price in a given region.

Compared with other related studies such as Cecchetti et al. (2002), Beck et al. (2009) and Tena et al. (2010), an important advantage of our database is that we are considering individual prices instead of disaggregate price indices that include a basket of products even at the disaggregate level. These indices could evolve differently simply because of different regional tastes for the items in the consumption basket and not because of the different dynamics of prices in the different regions.

\footnotetext{
3 The transport of commodities between Chilean cities is done by road. Therefore, the kilometric distance between locations is taken as the road (driving) distance, and our results apply to road transport.
} 
There are no observations for item 28 (fish) in the city of Punta Arenas, and therefore, we exclude information from this city for that product. Besides, the panel contains a small number of missing values that represent about $0.5 \%$ of the total number of observations. We tackle such data irregularities in a factor model framework by using the EM algorithm together with PC decomposition [see. e.g. Stock and Watson (2002) and Schumacher and Breitung (2008)]. More specifically, using the inflation information available for the 23 cities, we estimate the most important common factors for governing inflation in each of the 98 items (except product 28 observations of which are available for only 22 cities). Then, in a second step, the regression of each of the individual inflation series on the common factor is used to complete the missing values. The EM algorithm repeats steps 1 and 2 until convergence.

For a formal test on the number of unit roots in the panel, we follow Parsley and Wei (1996) by using the panel unit root test proposed by Levin et al. (2002). More precisely, for each of the 98 items, the basic regression specification is

$$
\Delta \pi_{k, t}=c_{k}+\beta \pi_{k, t-1}+\sum_{i=1}^{p} \gamma_{i} \Delta \pi_{k, t-1}+\varepsilon_{t}
$$

where $\pi_{k, t}$ is the annual growth rate of prices in city $k$ at time $t ; c_{k}$ is the constant term specific to the $k$ th city (i.e. we have a series of 23 dummies without constant term); and $\varepsilon_{t}$ is the error term.

The critical values of the Levin et al. (2002) panel unit root test for $T=25$ and $N=25$ (i.e. approximately our panel size) at the 1 and $5 \%$ significance levels are -8.27 and -7.74 , respectively. The results of this test indicate that the null hypothesis of non-stationarity could be rejected for $70 \%$ of the commodities at the $5 \%$ level. Thus, inflation can be considered as being generated by a stationary process in most cases but not all. For further checking, we also carried out a panel unit root test that allows for cross-sectional dependence (Pesaran 2006). This test rejected non-stationarity in all cases. Therefore, we consider inflation as a stationary process and test the impact of spatial variables on its evolution.

\section{Econometric specifications and results}

\subsection{Benchmark}

We initially estimate an equation that resembles the one proposed by Beck et al. (2009) in the sense that it considers the influence of national common factors at the national level on the dynamics of regional inflation. Indeed, to make our results comparable to Beck et al. (2009), we estimate common factors based on national macroeconomic variables such as the Chilean short-term interest rate, unemployment, the growth rate of oil prices, Chilean money supply, the nominal effective exchange rate, unit labour costs and industrial production. ${ }^{4}$ However, unlike them, we only consider a common factor at the national level and not at the continental level because there is not a

\footnotetext{
4 Appendix 2 contains a detailed description of these variables.
} 
common monetary policy for all South American countries. The resulting equation is estimated separately for each of the 98 commodities in the sample: ${ }^{5}$

$$
\pi_{k, t}=\alpha_{k}+\beta_{1} \pi_{k, t-1}+\beta_{2} f_{t}+\beta_{3} f_{t-1}+\varepsilon_{k, t}
$$

where $\pi_{k, t}$ is the annual inflation rate for the $k$ th city at time $t ; f_{t}$ is a national common factor; and $\varepsilon_{k, t}$ is the error term. This specification is denoted as Model 1.6

In order to establish a benchmark comparable with Beck et al. (2009), we exhibit a summary ${ }^{7}$ of the estimation results for Model 1 in the first column of Table 1 for the significance of each variable and in the third column of Table 1 for the explanatory power of each variable. The results show that for most commodities the dynamics of inflation are determined by its own past values and not by the common factor. The time-lagged dependent variable is significant for all commodities and explains on average $45 \%$ of the inflation variance, whilst the common factor is significant for only $40 \%$ of the commodities and explains only $16 \%$ of the inflation variance. Adjusting for the degrees of freedom, this model explains $46 \%$ of the inflation variance.

\subsection{Testing for spatial correlation}

Having established our benchmark results, our next step is to improve on the Beck et al. (2009) model by taking into account the presence of spatial correlation in the residuals of the model. In order to test for it, we define a weights matrix that takes positive values for cities in the same region and adjacent regions and zero otherwise. We do this by defining a spatial lag order as

$$
L^{(1)} \pi_{i}=\sum_{\substack{j \in G_{s} \\ j \neq i}} w_{i j}^{(1)} \pi_{j}
$$

where $G_{S}$ is the set of $s$ neighbours of order (1).

In this case, the weights $w_{i j}^{(1)}$ depend on the number of cities in the different regions. For example, if for a certain location, there are five different cities in the same region and adjacent regions, $w_{i j}^{(1)}=1 / 5$ for each of the five cities, and zero for the remaining

\footnotetext{
5 Regressing separately for each of the 98 commodities in the sample can be seen as assuming independence between the markets. However, note that this approach is in fact less restrictive as it allows for parameters to vary across commodities. In any case, in Sect. 5, we run regressions using product groups to be able to further examine the sign and significance of the coefficients.

6 The factor estimation method is explained in detail by Beck et al. (2009). The model includes the timelagged dependent variable, which is potentially endogenous. However, using Monte Carlo simulations, Beck and Katz (2004) find that the nickel bias is low (2\% or less) once, and they advise the use of a least-square estimator with a time-lagged dependent variable included if is at least 20. Our sample contains 45 months; hence, we do not correct for endogeneity of the time-lagged dependent variable. Nevertheless, in Sect. 5, we control for endogeneity issues.

7 Due to the large number of commodities used, only a summary of results is presented. The full set of results is available with the authors.
} 
Table 1 Regression results for the benchmark models

\begin{tabular}{|c|c|c|c|c|}
\hline & \multicolumn{2}{|c|}{$\begin{array}{l}\text { Percentage of commodities } \\
\text { for which each variable is } \\
\text { significant }(5 \%)\end{array}$} & \multicolumn{2}{|c|}{$\begin{array}{l}\text { Average share of } \\
\text { variance explained } \\
\text { by each variable }\end{array}$} \\
\hline & Model 1 & Model 2 & Model 1 & Model 2 \\
\hline Time-lagged dependent variable & $100 \%$ & $100 \%$ & $45 \%$ & $45 \%$ \\
\hline Neigbour & - & $81 \%$ & - & $7 \%$ \\
\hline Time-lagged neighbour & - & $32 \%$ & - & $21 \%$ \\
\hline Common factor beck & $41 \%$ & $10 \%$ & $16 \%$ & $16 \%$ \\
\hline Time-lagged common factor beck & $40 \%$ & $9 \%$ & $16 \%$ & $16 \%$ \\
\hline Common factor commodity & - & - & - & - \\
\hline Time-lagged common factor commodity & - & - & - & - \\
\hline Common factor city & - & - & - & - \\
\hline Time-lagged common factor city & - & - & - & - \\
\hline Aggregate Chilean inflation rate & - & $23 \%$ & - & $15 \%$ \\
\hline Time-lagged aggregate inflation rate & - & $16 \%$ & - & $15 \%$ \\
\hline Whole specification (adjusted $\mathrm{R}^{2}$ ) & & & $46 \%$ & $48 \%$ \\
\hline \multicolumn{5}{|l|}{ Testing the models } \\
\hline$F$-test for overall significance ${ }^{\mathrm{a}}$ & $100 \%$ & $100 \%$ & & \\
\hline LM test for second order spatial contiguity ${ }^{a}, \mathrm{~b}$ & $60 \%$ & $56 \%$ & & \\
\hline Heteroskedasticity and independency test ${ }^{\mathrm{a}}$ & $100 \%$ & $100 \%$ & & \\
\hline Variance inflation factor ${ }^{\mathrm{c}}$ & 34.99 & 33.24 & & \\
\hline Condition number ${ }^{\mathrm{c}}$ & 14.78 & 29.03 & & \\
\hline Bayesian information criterion & 1595.7 & 1593.2 & & \\
\hline
\end{tabular}

Model 1 baseline model (Beck et al. 2009 common factor); Model 2 augmented model considering neighbours

a Percentage of rejection at the $5 \%$ significance level

${ }^{\mathrm{b}}$ Model 1 is not a spatial model and in this case we run a standard LM test to check for the existence of spatial correlation

${ }^{\mathrm{c}}$ Average value for all the commodities

ones. Therefore, the following properties are met: 1) $w_{i j}^{(s)} \geq 0$;2) $w_{i i}^{(s)}=0$; and 3) $\sum_{\substack{j \in G_{s} \\ j \neq i}} w_{i j}^{(s)}=1$ [see, for example, Anselin (1988) and Arbia (2006)].

We carried out several tests for the presence of spatial correlation in the residuals of specification (4.1), such as Moran's I-statistic, the likelihood ratio test, the Wald test and the Lagrange multiplier test. The results of all the aforementioned tests indicate that the null of no spatial correlation could be rejected in more than $60 \%$ of the commodities at the $5 \%$ significance level. ${ }^{8}$ These results suggest that specification (4.1) could be improved by taking into account the interrelations of each city with other cities in the same and adjacent regions. Therefore, we augment the previous model by considering the following specification:

\footnotetext{
8 See, Anselin (1988) for a definition of the weights matrix in spatial econometric models and for different tests of spatial correlation.
} 


$$
\begin{aligned}
\pi_{k, t}= & \alpha_{k}+\beta_{1} \pi_{k, t-1}+\beta_{2} L^{(1)} \pi_{k, t}+\beta_{3} L^{(1)} \pi_{k, t-1}+\beta_{4} f_{t} \\
& +\beta_{5} f_{t-1}+\beta_{6} \pi_{t}+\beta_{7} \pi_{t-1}+\varepsilon_{k, t}
\end{aligned}
$$

where $\pi_{t}$ is the annual growth rate of the Chilean consumer price index. This augmented model is denoted as Model 2.

This specification allows us to take into account spatial correlation in the inflation rates of the different cities and also the influence of the general inflation rate for each product. Note, however, that the likelihood function for Eq. (4.3) cannot be maximized analytically due to the high degree of nonlinearity in the parameters. Therefore, we approximate this estimation by making use of the pseudo-likelihood procedure in LeSage (1999a). ${ }^{9}$ This procedure involves the optimization of the likelihood function of model (4.3) under the constraint that the spatial lagged parameter is bounded to be between the inverse of the minimum and maximum of the spatial contiguity matrix. Another interesting implementation issue of this methodology is that the estimation of the spatial parameter is robust as its dispersion is obtained by evaluating the numerical hessian matrix of the likelihood function.

The results of estimating Model 2 reveal the presence of space-dependency in $81 \%$ of the commodities, whilst the common factor determines inflation for only $10 \%$ of them, which means that the introduction of space-dependency renders the common factor insignificant in $30 \%$ of the commodities (Table 1, second column). On average, the common factor explains $16 \%$ of the observed inflation variance, with the inflation of neighbouring regions explaining $7 \%$ contemporaneously and $21 \%$ with a one period time lag (Table 1 , fourth column). This result confirms the theoretical hypothesis of Sect. 2 according to which distance (transport cost) determines prices contemporaneously to some extent, but with a one-period time lag to a higher extent. Overall, we are able to increase the adjusted $R^{2}$ to $48 \%$.

Our empirical results for Models 1 and 2 are at odds with what Beck et al. (2009) had found for Europe, where the macroeconomic common factor was the most important determinant of inflation dynamics. Moreover, the finding that neighbours matter more than common factors (even if with a time lag) justifies the introduction of spatially lagged variables in models of determination of regional inflation.

We conduct a further check that Model 2 does not contain spatial correlation. More specifically, we consider a second order of contiguity by defining regions that are neighbours of neighbours, $L^{(2)}$, and we use the test proposed by LeSage (1999b) based on the residuals from the spatial autoregressive (SAR) model to examine whether inclusion of the spatial lag term eliminates spatial dependence in the residuals of the model. In this test, we allow for the presence of the spatial lagged variable in the model. Then, the test is conditional on having spatial lagged parameters not equal to zero in the model rather than relying on standard OLS residuals. We test for the presence of second order spatial contiguity in Model 2 finding evidence of additional spatial autocorrelation in $56 \%$ of cases. However, this is not problematic because, as we will

\footnotetext{
9 This simultaneous equations model may present simultaneity problems. We start by assuming that the prices of neighbour cities can be regarded as exogenous with respect to the prices in each city as they are a weighted average of a set of prices. In Sect. 5, we relax this assumption and conduct some robustness checks of our results under simultaneity.
} 
Table 2 Regression results for various robustness checks

\begin{tabular}{|c|c|c|c|c|c|c|c|c|}
\hline & \multicolumn{4}{|c|}{$\begin{array}{l}\text { Percentage of commodities for which } \\
\text { each variable is significant }(5 \%)\end{array}$} & \multicolumn{4}{|c|}{$\begin{array}{l}\text { Average share of variance explained } \\
\text { by each variable }\end{array}$} \\
\hline & Model 3 & Model 6 & Model 4 & Model 5 & Model 3 & Model 6 & Model 4 & Model 5 \\
\hline Time-lagged dependent variable & $98 \%$ & $95 \%$ & $99 \%$ & $100 \%$ & $45 \%$ & $45 \%$ & $45 \%$ & $45 \%$ \\
\hline Neighbour & $76 \%$ & $53 \%$ & - & - & $25 \%$ & $7 \%$ & - & - \\
\hline Time-lagged neighbour & $13 \%$ & $44 \%$ & - & - & $23 \%$ & $23 \%$ & - & - \\
\hline Common factor beck & - & - & $93 \%$ & $36 \%$ & - & - & $27 \%$ & $16 \%$ \\
\hline Time-lagged common factor beck & - & - & $93 \%$ & $40 \%$ & - & - & $27 \%$ & $16 \%$ \\
\hline Common factor commodity & $89 \%$ & $67 \%$ & - & - & $31 \%$ & $31 \%$ & - & - \\
\hline $\begin{array}{l}\text { Time-lagged common factor } \\
\text { commodity }\end{array}$ & $58 \%$ & $59 \%$ & - & - & $26 \%$ & $26 \%$ & - & - \\
\hline Common factor city & - & - & - & $53 \%$ & - & - & - & $10 \%$ \\
\hline Time-lagged common factor city & - & - & - & $53 \%$ & - & - & - & $9 \%$ \\
\hline Aggregate Chilean inflation rate & $5 \%$ & $29 \%$ & - & - & $15 \%$ & $15 \%$ & - & - \\
\hline Time-lagged aggregate inflation rate & $4 \%$ & $17 \%$ & - & - & $15 \%$ & $15 \%$ & - & - \\
\hline Whole specification (adjusted $R^{2}$ ) & & & & & $47 \%$ & $52 \%$ & $51 \%$ & $48 \%$ \\
\hline \multicolumn{9}{|l|}{ Testing the models } \\
\hline$F$-test for overall significance ${ }^{a}$ & $98 \%$ & $100 \%$ & $100 \%$ & $100 \%$ & & & & \\
\hline $\begin{array}{l}\text { LM test for second-order spatial } \\
\text { contiguity } \mathrm{a}, \mathrm{b}\end{array}$ & $15 \%$ & $15 \%$ & $66 \%$ & $60 \%$ & & & & \\
\hline $\begin{array}{l}\text { Heteroskedasticity and } \\
\text { independency test }{ }^{\mathrm{a}}\end{array}$ & $100 \%$ & $100 \%$ & $100 \%$ & $100 \%$ & & & & \\
\hline Variance inflation factor ${ }^{\mathrm{b}}$ & 17.23 & 17.23 & 34.99 & 23.21 & & & & \\
\hline Condition number ${ }^{\mathrm{c}}$ & 24.81 & 24.81 & 14.78 & 15.42 & & & & \\
\hline Bayesian information criterion $^{c}$ & 1596.1 & 1562.8 & 1562.4 & 1580.0 & & & & \\
\hline
\end{tabular}

Model 3 national common factor for each commodity with contiguity matrix based on distance; Model 6 GMM estimation of Model 3; Model 5 Model 1 with city-specific loading factors; Model 6 Model 1 with a city common factor. In each row of the table, the average share of variance shown is the average of the $R^{2}$ 's obtained in one regression for each commodity where the only explanatory variable is the one indicated in that row

${ }^{\text {a }}$ Percentage of rejection at the $5 \%$ significance level

b Models 4 and 5 are not spatial models and in these cases we run standard LM tests to check for the existence of spatial correlation

c Average value for all the commodities

discuss in the following section, the evidence of spatial second-order autocorrelation is reduced to only $15 \%$ of cases in most relevant models (see Table 2).

Anselin (1987) demonstrated that, in the presence of positive spatial dependence in the sampling model, the Breusch-Pagan test presents a bias towards the alternative hypothesis of heteroscedasticity, while the White test shows a bias in favour of the null hypothesis of homoscedasticity. Anselin (1988) proposed to consider a joint test statistic to check for both the homoscedasticity and the independence hypothesis simultaneously. Specifically, the joint spatial heteroscedasticity and independence test is expressed as the sum of the Breusch-Pagan $t$-statistic and the Lagrange multiplier test for the spatial independence hypothesis. This statistic is distributed as a $\chi^{2}$ with $k$ degrees of freedom. 
As shown in Tables 1 and 2, residuals still show spatial autocorrelation and heteroscedasticity in all cases. We have dealt with this problem by using robust estimations such as the pseudo-likelihood procedure in LeSage (1999a), which estimates the parameter dispersion by evaluating the numerical hessian matrix of the likelihood function, or the different GMM estimates that are robust in all cases. Also, as expected, the variance inflation factor and the condition number suggest the presence of high multicolinearity among the variables in the model. Indeed, the time and spatial lags of each commodity price as well as the different national variables are highly correlated. In spite of this, $t$-statistics of the different parameters of the model are significant at the conventional levels.

\section{Robustness checks}

\subsection{Commodity-specific shocks}

The fact that a macroeconomic common factor is not an important variable to describe inflation dynamics in many commodities does not necessarily mean that an important part of the dispersion observed in the various commodity prices is not affected by a common shock at the national level. It could be the case that there are shocks specific to each commodity. This possibility is tested by obtaining a national common factor for each of the commodities from the inflation dynamics for that item in the 23 cities and estimating a model similar to (4.3) where the Beck common factor is replaced by a commodity common factor. ${ }^{10}$ The commodity-specific common factor is significant in $91 \%$ of the regressions compared to the $10 \%$ found for the Beck common factor, and it explains $31 \%$ of inflation dynamics compared to the $16 \%$ of the Beck common factor. However, also in this case, spatial variables have a significant impact on the determination of prices for $62 \%$ of the commodities and do not lose explanatory power.

\subsection{Distance-based spatial weights matrix}

One potential drawback of our empirical results is the ad hoc consideration of the weights matrix. In fact, the choice of weights is typically a discretionary decision made by the researcher, and the results could be sensitive to the selection of neighbours. To deal with this problem, we consider a weight matrix based on kilometre distances instead of adjacent regions. That is, in this case, $w_{i j}$ is defined as the distance from city $i$ to $j$ divided by the sum of distances from $i$ to all the other 22 cities. Then, we use again the test proposed by LeSage (1999b) on the model described in the previous subsection to check if its residuals still contain evidence of spatial correlation based on distance. We find that the null of no spatial correlation is rejected in $64 \%$ of the regressions at the $5 \%$ significance level. If, on the contrary, we consider a model with

$\overline{10}$ A summary of results is available from the authors. 
an autoregressive spatial lag based on distance and we test for additional contiguity spatial autocorrelation, the null hypothesis is rejected in only $13 \%$ of the cases at the $5 \%$ significance level. This result suggests that spatial autocorrelation is better captured by using a weight matrix based on distance.

Moreover, if we test for the presence of second-order spatial autocorrelation in the residuals of a model that already includes a spatial lag based on distance, the null hypothesis of no correlation is rejected in only $15 \%$ of the cases (see Table 2). If we were using data for a country geographically shaped like France or Spain, then the lack of significance of the second-order contiguity could be explained by noting that the spatially lagged variable would, in those cases, be the average of almost all the spatial observations. However, we are using data for Chile and, due to the country's unique ribbon-like shape, each region has at most two first-order neighbours and four second-order neighbours, far from the total of 23 observations. In our data, the average for all neighbours is represented by the common factor, whilst the spatial lag represents the higher level of integration of neighbouring regions.

Given this result, a commodity common factor model was estimated using a contiguity matrix based on distance (call it Model 3). The weights matrix $w_{i, j}$ is now defined a priori such that its characteristic element $w_{i, j}$ measures the inverse of the driving distance between cities $i$ and $j$ once the rows of each of the matrices are scaled so that the sum of all the elements in a row sum to 1 to fulfill the conditions in Anselin (1988). As can be seen in Table 2, spatial variables became significant in $76 \%$ of the commodities under this specification and now explain $25 \%$ of inflation variance, which suggests that, consistently with our hypothesis, it is geographical distance and not administrative boundaries that determine the transmission of inflation across neighbour cities.

It is possible to conclude from this analysis that, consistently with the theory, spatial factors play a key role in the determination of Chilean inflation. Moreover, geographical distance seems to be a more appropriate measure of neighbourhood than the adjacency of regions. Common macroeconomic factors do not explain an important proportion of commodity price dynamics; however, national factors that are specific to each commodity turn out to be important explanatory variables.

\subsection{Non-stationarity}

In order to address the issue of non-stationarity, we consider a similar estimation to Model 3 using variables in first differences. ${ }^{11}$ This specification makes sense given that, although the unit root tests reported in Sect. 3 had suggested that inflation is a stationary process, the evidence is not compelling (it was found for around $70 \%$ of the cases). The results of the first-difference estimation confirm that spatial variables also play an important role on the determination of the first differences of inflation for the various commodities. Contemporaneous neighbour inflation is significant for $71 \%$ of the commodities, although the share of variance of inflation first differences that is explained by that variable is negligible.

\footnotetext{
11 Again these results are omitted but are available from the authors.
} 


\subsection{Location-specific inflation dynamics}

We also allow for inflation dynamics to differ across cities by rebuilding Model 1 under the assumption of city-specific loading factors (Model 4) and the additional assumption of city-specific common factors (Model 5). The Moran, LR, Wald and LM tests for these two models reject the absence of spatial autocorrelation at the $5 \%$ significance level in most cases (around $70 \%$ in Model 4 and $60 \%$ in Model 5), thus the use of spatial models is justified also for these two specifications. As can be seen in Table 2, their explanatory power does not improve upon that of Model 1, but the common factor built with city-specific loading factors is significant for $93 \%$ of the commodities in Model 4, whilst in Model 5, it compares to that of Model 1. In addition, in Model 5, the city-specific common factor is significant in $53 \%$ of the commodities.

\subsection{Endogeneity}

Specification (4.3) presents a spatial lagged value $L^{(1)} \pi_{\mathrm{k}, \mathrm{t}}$ that will generally be correlated with the disturbance $\varepsilon_{\mathrm{k}, \mathrm{t}}$. We address this endogeneity issue by means of two different approaches. ${ }^{12}$

First, we estimate a model similar to Model 3 using the Generalized Method of Moments (GMM) estimator and denote the new model as Model 6. GMM is a robust estimator in that, unlike maximum likelihood estimation, it does not require information of the exact distribution of the disturbances. The GMM estimator selects parameter estimates so that the sample correlations between the instruments and the model are as close to zero as possible (see for example Hall 2005). Under GMM estimation, spatial variables exert an even more important role in the determination of inflation for the different commodities. Contemporaneous and time-lagged inflation in nearby cities are now significant for respectively 53 and $44 \%$ of the commodities and they jointly explain $30 \%$ of inflation variance (see Table 2 ).

Our second approach to dealing with endogeneity is the use of a Generalized Spatial Two Stage Least Squares (GS2SLS) estimation, which is especially suited to spatial models. ${ }^{13}$ Consider a model similar to that expressed in (4.3) except for the fact that the disturbance process is known to follow a first-order spatial autoregressive process:

$$
\varepsilon_{k, t}=\rho L^{(1)} \varepsilon_{k, t}+\xi_{k, t}
$$

where the innovation $\xi_{k, t}$ is assumed to have zero mean and non-constant variance $\boldsymbol{\sigma}_{i}^{2}$ and is independent of $\xi_{i, j}$ for $\boldsymbol{i} \neq \boldsymbol{k}$ and $\boldsymbol{t} \neq \boldsymbol{j}$.

\footnotetext{
12 The instruments used are common factor (contemporaneous and first time-lag); national inflation (contemporaneous and first two time-lags); neighbour inflation (up to the fifth time-lag); dependent variable (second to fifth time-lags). The results are robust to the selected time-lags. We have used the Hansen test to study if instruments are strong and valid. At the $5 \%$ significance level, we can accept that the residuals of the estimation are uncorrelated with all exogenous variables (i.e. the exogenous variables and the instrumental variables) in 98 and $67 \%$ of the cases for the GMM and the General spatial 2SLS estimation respectively. We could also reject the hypothesis of weak instruments in 100 and $99 \%$ of the cases for the GMM and the General spatial 2SLS estimation respectively.

13 We thank an anonymous referee for suggesting this approach.
} 
Kelejian and Prucha (2010) define a GS2SLS estimation for $\rho$ and provide results under both consistency and asymptotic normality. They also give results for the joint asymptotic distribution of the Generalized Moments (GM) estimator for $\boldsymbol{\rho}$ and $\boldsymbol{\beta}_{2}$. The spatial 2SLS (S2SLS) regression can be seen as a straightforward extension of the 'classical' 2SLS procedure. A detailed description of this procedure can be found in Kelejian and Prucha (1998, 2010). Intuitively, the estimation consists of two steps combining GM and Instrumental Variables (IV) estimators. Each of the two steps includes sub-steps. The first step estimates the parameter of the model by spatial twostage least squares and employs the residuals to obtain an estimation of $\rho$ by GM. Then, the estimator for $\rho$ is used to take a spatial Cochrane-Orcutt transformation of the model, and in the second step, the transformed model is estimated by S2SLS: this is the GS2SLS estimator (see Kelejian and Prucha 1998).

This estimation procedure can be easily implemented by using, for example, the $\mathrm{R}$ package sphet (Piras 2010) or the spreg and spivreg STATA commands (see Drukker et al. 2011a,b). In these applications, the matrix of instruments can be defined in the following way:

$$
\boldsymbol{H}=\left(\boldsymbol{X}, \boldsymbol{L}^{(\mathbf{1})} \mathbf{X}, \ldots,\left(\boldsymbol{L}^{(\mathbf{1})}\right)^{q} \mathbf{X}\right)
$$

where $\mathbf{X}$ is a vector containing all the non-endogenous variables in our model, and typically, $\boldsymbol{q} \leq 2$.

This selection of instruments constitutes an approximation to ideal instruments based on the reduced form of the model (for an extensive discussion on this issue see Kelejian and Prucha 1998; Kelejian et al. 2004; among others). It would be interesting to replicate the estimation of Model 4 based on this procedure, however, in our particular model, it is not feasible to use the instruments proposed by the available econometric packages because some of the explanatory variables are defined at the national level, i.e. $\pi_{t}, f_{t}$ and their time-lagged values, and there is perfect multicollinearity between each of these variables and their spatial neighbours. We circumvent this problem by making use of the Frisch-Waugh theorem. Then, in the first step, we regress $\pi_{k, t}$ on the set of city dummies, $\boldsymbol{f}_{\boldsymbol{t}}, \boldsymbol{f}_{\boldsymbol{t}-1}, \boldsymbol{\pi}_{\boldsymbol{t}}, \boldsymbol{\pi}_{t-1}$ and save the residuals, calling it $\boldsymbol{r}_{0, \boldsymbol{k}, \boldsymbol{t}}$. We also regress $\boldsymbol{\pi}_{k, t-1}, L^{(\mathbf{1})} \boldsymbol{\pi}_{k, t}$ and $\boldsymbol{L}^{(\mathbf{1})} \boldsymbol{\pi}_{k, t-1}$ on the set of city dummies, $\boldsymbol{f}_{t}, \boldsymbol{f}_{t-1}, \boldsymbol{\pi}_{t}, \boldsymbol{\pi}_{t-1}$ and call the residuals of each of these regressions $\boldsymbol{r}_{1, k, t}, \boldsymbol{r}_{2, \boldsymbol{k}, \boldsymbol{t}}$ and $\boldsymbol{r}_{3, \boldsymbol{k}, t}$ respectively. Then, in the second step, we estimate the following regression by general spatial $2 \mathrm{SLS}:{ }^{14}$

$$
\boldsymbol{r}_{0, k, t}=\boldsymbol{\beta}_{1} \boldsymbol{r}_{1, k, t}+\boldsymbol{\beta}_{2} \boldsymbol{r}_{2, k, t}+\boldsymbol{\beta}_{3} \boldsymbol{r}_{3, k, t}+\boldsymbol{\varepsilon}_{\boldsymbol{k}, t}
$$

Note that the parameters in (5.2) are comparable to those in (4.3). The results of the estimation of specification (5.2) for the different Chilean cities are reported in Table 3. These results provide additional empirical evidence on the fact that spatial proximity plays an important role in the determination of inflation in the different commodities. The null of no contemporaneous spatial dependence, $\boldsymbol{H}_{0}: \boldsymbol{\beta}_{2}=\boldsymbol{\rho}=0$, is rejected in $50 \%$ of the cases at the $5 \%$ level, which provides robust evidence that geographical

\footnotetext{
14 For this estimation, we used the sphet package in $\mathrm{R}$ as it is freely available and can be easily applied to our model.
} 
Table 3 General spatial 2SLS estimation

\begin{tabular}{|c|c|c|c|c|}
\hline & \multicolumn{2}{|c|}{$\begin{array}{l}\text { Percentage of commodities for } \\
\text { which each variable is } \\
\text { significant }(5 \%)\end{array}$} & \multicolumn{2}{|c|}{$\begin{array}{l}\text { Average share of variance } \\
\text { explained by each variable }\end{array}$} \\
\hline & $\begin{array}{l}\text { First } \\
\text { step }(\%)\end{array}$ & $\begin{array}{l}\text { Second } \\
\text { step }(\%)\end{array}$ & $\begin{array}{l}\text { First } \\
\text { step }(\%)\end{array}$ & $\begin{array}{l}\text { Second } \\
\text { Step }\end{array}$ \\
\hline Time-lagged dependent variable & - & 98 & - & 29 \\
\hline Neighbour $\left(\beta_{2}\right)$ & - & 9 & - & - \\
\hline Neighbour $(\rho)$ & - & 23 & - & - \\
\hline Neighbour $\left(\beta_{2}+\rho\right)$ & - & 50 & - & 3 \\
\hline Time-lagged neighbour & - & 15 & - & 1 \\
\hline Common factor commodity & 88 & - & 31 & - \\
\hline $\begin{array}{l}\text { Time-lagged common } \\
\text { factor commodity }\end{array}$ & 7 & - & 26 & - \\
\hline Aggregate Chilean inflation rate & 3 & - & 15 & - \\
\hline $\begin{array}{l}\text { Time-lagged aggregate } \\
\text { inflation rate }\end{array}$ & 2 & - & 15 & - \\
\hline Whole specification (adjusted $R^{2}$ ) & - & - & 32 & 30 \\
\hline
\end{tabular}

The results shown correspond to the estimation of Eq. (5.2), which is the generalized estimation of Model 4. Coefficients show the percentage of commodities for which each variable is significant. Explained variance shows the average share of variance explained by each variable, which, for the whole specification, corresponds to an adjusted $R^{2}$

driving distance still plays a remarkable role in the dynamics of Chilean inflation even when we control for national common factors and time-lagged inflation.

\subsection{Measures of distance}

In Sect. 4, we have used the kilometric driving distance between cities. We now estimate a model similar to Model 3 under two alternative measures of distance: (i) using a weighted matrix based on the Euclidean distance between each pair of cities (based on measures of latitude and longitude for each city); and (ii) using the distance of each city to the capital of the country, Santiago de Chile. The estimation results are presented in Table 4.

One important point to note is that the distance to Santiago is significant in a high proportion of commodities (though not in as high a proportion as the driving distance between cities). This could be because the capital city constitutes a hub either for most trade operations or simply to its location given that it is in the centre of the country and it is the most likely neighbour to many other cities.

\section{Interpreting the coefficient signs}

\subsection{Distribution across commodities}

Since we have carried out separate regressions for each of the 98 commodities, it would be impossible to present all the results in a meaningful way. However, to provide some 
Table 4 Estimation of Model 3 with alternative measures of distance

\begin{tabular}{|c|c|c|c|c|}
\hline & \multicolumn{2}{|c|}{$\begin{array}{l}\text { Percentage of commodities for } \\
\text { which each variable is } \\
\text { significant }(5 \%)\end{array}$} & \multicolumn{2}{|c|}{$\begin{array}{l}\text { Average share of variance } \\
\text { explained by each variable }\end{array}$} \\
\hline & $\begin{array}{l}\text { Euclidean } \\
\text { distance }(\%)\end{array}$ & $\begin{array}{l}\text { Distance to } \\
\text { Santiago }(\%)\end{array}$ & $\begin{array}{l}\text { Euclidean } \\
\text { distance }(\%)\end{array}$ & $\begin{array}{l}\text { Distance to } \\
\text { Santiago }(\%)\end{array}$ \\
\hline Time-lagged dependent variable & 97 & 97 & 45 & 45 \\
\hline Neighbour & 57 & 87 & 7 & 7 \\
\hline Time-lagged neighbour & 2 & 6 & 8 & 8 \\
\hline Common factor commodity & 89 & 90 & 31 & 31 \\
\hline $\begin{array}{l}\text { Time-lagged common } \\
\text { factor commodity }\end{array}$ & 74 & 77 & 26 & 26 \\
\hline Aggregate Chilean inflation rate & 3 & 5 & 15 & 15 \\
\hline $\begin{array}{l}\text { Time-lagged aggregate } \\
\text { inflation rate }\end{array}$ & 3 & 5 & 15 & 15 \\
\hline $\begin{array}{l}\text { Whole specification } \\
\text { (adjusted } R^{2} \text { ) }\end{array}$ & & & 52 & 52 \\
\hline
\end{tabular}

indication as to the direction of the effect of each variable, we collected the significant coefficients for Model 3 (at the $5 \%$ significance level) and represented them in a histogram for each explanatory variable (Fig. 1). ${ }^{15}$

The economics literature does not provide a clear indication of how regional and sectoral shocks impact the dynamic of prices. Recent studies by Boivin et al. (2009) and Mackoviak et al. (2009) decompose a large set of disaggregate monthly US sectoral consumer price data into aggregate and sectoral components, finding that the aggregate component contributes only little to changes in sectoral prices, while the sectoral components explain most of the movements. A more recent contribution by Beck et al. (2011) considers 11 sectors in 61 regions of EMU member countries and estimates the role of sectors and regions in explaining price movements. They estimate that countryspecific and country-specific sectoral components together explain about $30 \%$ of price variance, while the regional component explains about $13 \%$. They conclude that in general consumers and producers are more attentive to region-specific shocks than to aggregate shocks.

It is difficult to extrapolate these results to our analysis as this is a relatively new branch of the economic literature, and there is not enough evidence for developing countries. However, we can hypothesize that prices in a homogeneous and large country such as Chile should show positive and significant reactions mainly to country-

\footnotetext{
15 We prefer to consider model 3 in all cases given that it is a more general model that also encompasses the case in which spatial parameters are equal to zero. However, we have also observed how the histograms of parameters of model 3 in Fig. 1 are altered when we consider instead model 1 for the cases in which the null of no spatial dependence has not been rejected at the $5 \%$ level. The main conclusions are not altered if we had followed this alternative procedure. This other figure is available from the authors upon request.
} 
Time lagged dependent variable

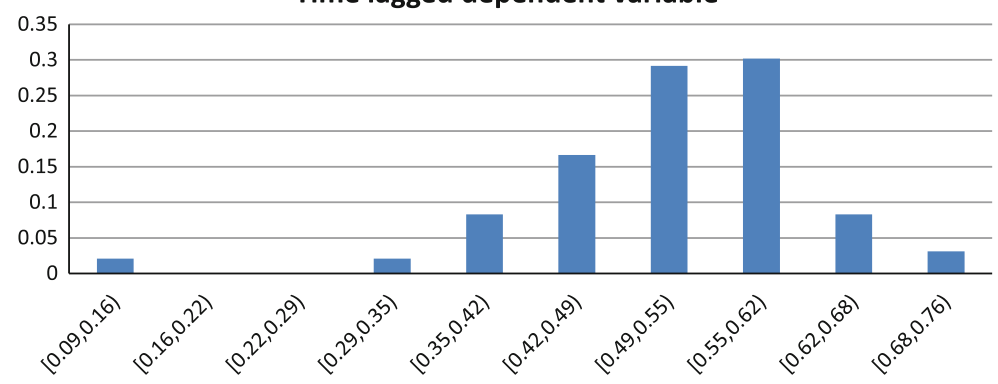

Neighbour

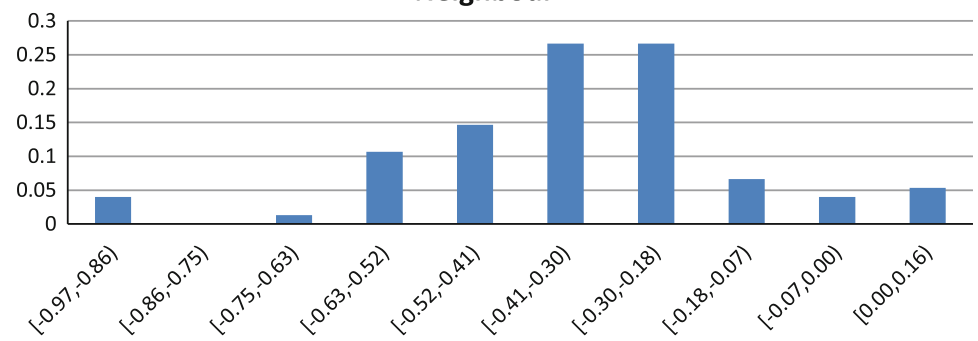

Time lagged neighbour

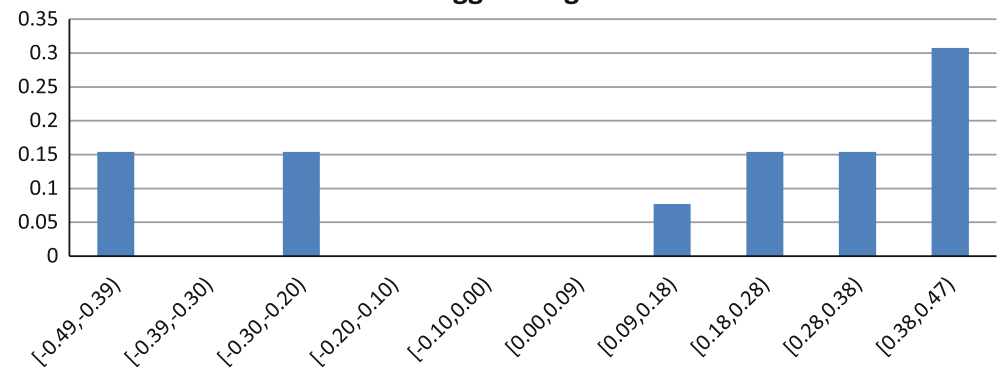

\section{Common factor commodity}

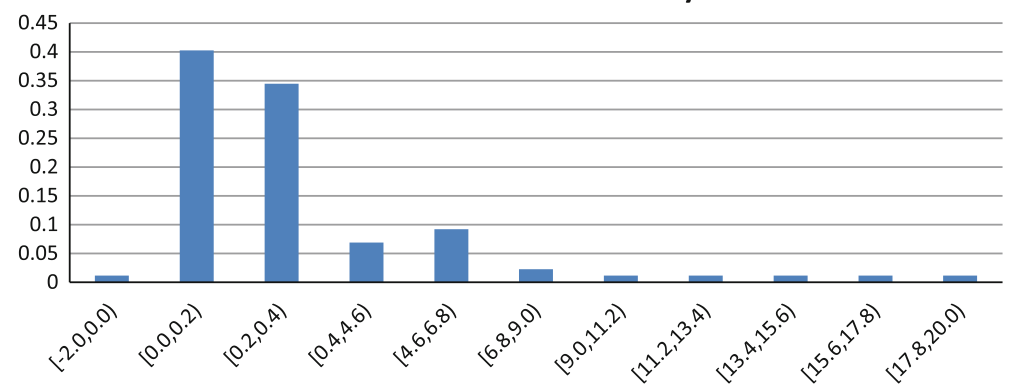

Fig. 1 Histograms for the significant parameters in Model 3 (at $5 \%$ ) 
Time lagged common factor commodity
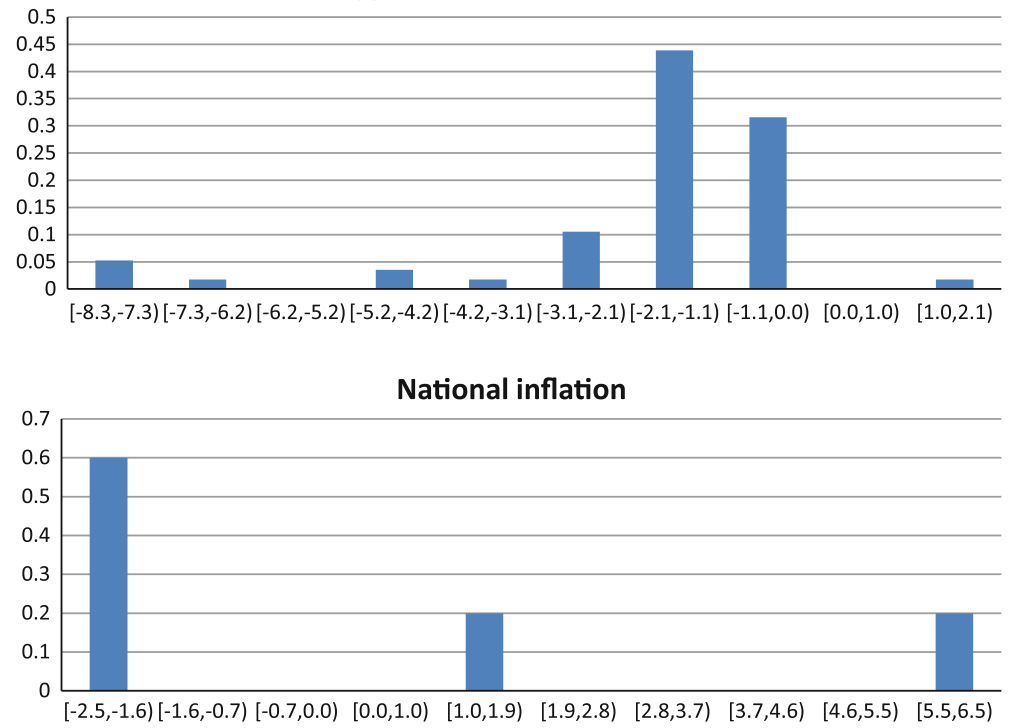

Time lagged national inflation

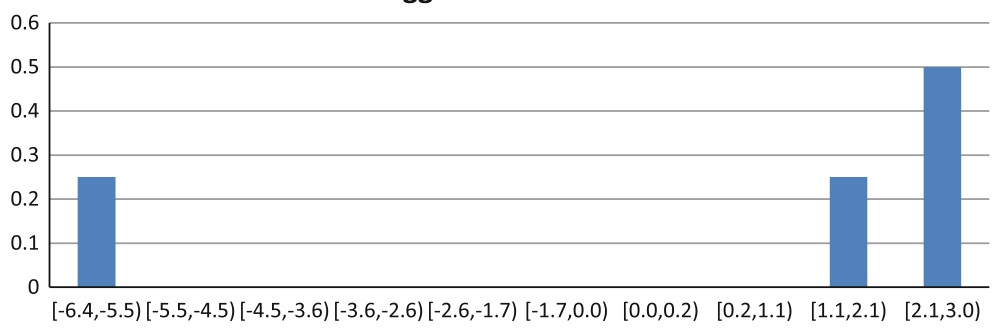

Fig. 1 continued

specific sectoral shocks and sectoral shocks in neighbour regions, while producers and consumers could be less attentive to aggregate national shocks.

In Fig. 1 it is possible to identify that the coefficients of the time-lagged dependent variable cluster around $0.5-0.6$. Those of neighbour cities' prices start out as negative, but seem to become positive for most commodities after a one period time-lag. This long-term result is in line with what would be expected from theory (positive correlation between prices in different cities). In the short term, however, nominal rigidities prevent a quick price adjustment, and an apparent contemporaneous substitution can be observed. The commodity common factor exerts a positive contemporaneous impact on inflation, but its time-lagged impact is negative. However, in line with economic intuition, we find that the long-term effect of the common factor on prices is positive in all cases. Since we also find a positive long-term effect for neighbouring prices, we conclude that commodity prices across the various geographical areas are positively correlated. 


\subsection{Independence of markets and product grouping}

So far, we have carried out regressions for each of the 98 commodities separately. Whilst this approach is less restrictive because it allows for parameters to vary across commodities, it becomes cumbersome in terms of presentation of the results. Therefore, to be able to further examine the sign and significance of the coefficients in a meaningful way, we group the 98 commodities into 12 groups according to product categories (these are described in Appendix 2). This grouping can be justified by the similarity of value per weight unit of the products included in each group, which originates groups with similar transport costs. We then carry out for each group the baseline procedure used in the previous section - the pseudo-likelihood procedure in LeSage (1999a) — and present those results in Table 5. They are comparable to those of Model 3 , but now we are able to present the estimated coefficients for each group. Note, however, this significance of an explanatory variable for one group does not necessarily mean significance for each product in that group, especially for those groups with a higher number of products. Hence, when comparing product-level with group-level results, one needs to exert some care.

Overall, the results in Table 5 (estimation by groups) are in line with the histograms in Fig. 1 (estimation by products). Spatial proximity clearly affects 9 groups out of 12 with a negative contemporaneous correlation and 2 groups out of 12 with a positive time-lagged correlation. The share of inflation variance explained by the spatial variables, although varying across product groups, presents mean values close to those of Model 3 in Table 2. Therefore, the group-level regressions confirm the importance of spatial transmission of prices that had been found also in product-level regressions. Linked to this finding, time-lagged inflation is significant in all product groups and has the greatest explanatory power (except for gasoline), confirming that the persistence of inflation divergence can be jointly explained by price stickiness and transport costs.

\section{Concluding remarks}

We have analysed the determinants of inflation for 98 commodities distributed across 12 commodity groups in 23 major Chilean cities. The results obtained indicate that inflation differentials can be observed across regions that are affected by the same type of macroeconomic shocks. One possible explanation for this finding is the key role played by geographical distance in the determination of inflation rates for the different cities. These empirical results are consistent with a model with sticky prices where the location of firms in the different regions of a country together with transport costs could explain inflation divergence that is persistent through time.

Future lines of research are suggested by this study. First, it would be interesting to augment the theoretical model to explain endogenously the evolution of transport costs. In this way, it should be possible to analyse the implications of different types of worldwide economic shocks at the regional level. The second extension relates to the analysis of monetary policy. Given that inflation could diverge across regional areas, central bankers should consider the various sources of inflation heterogeneity to 


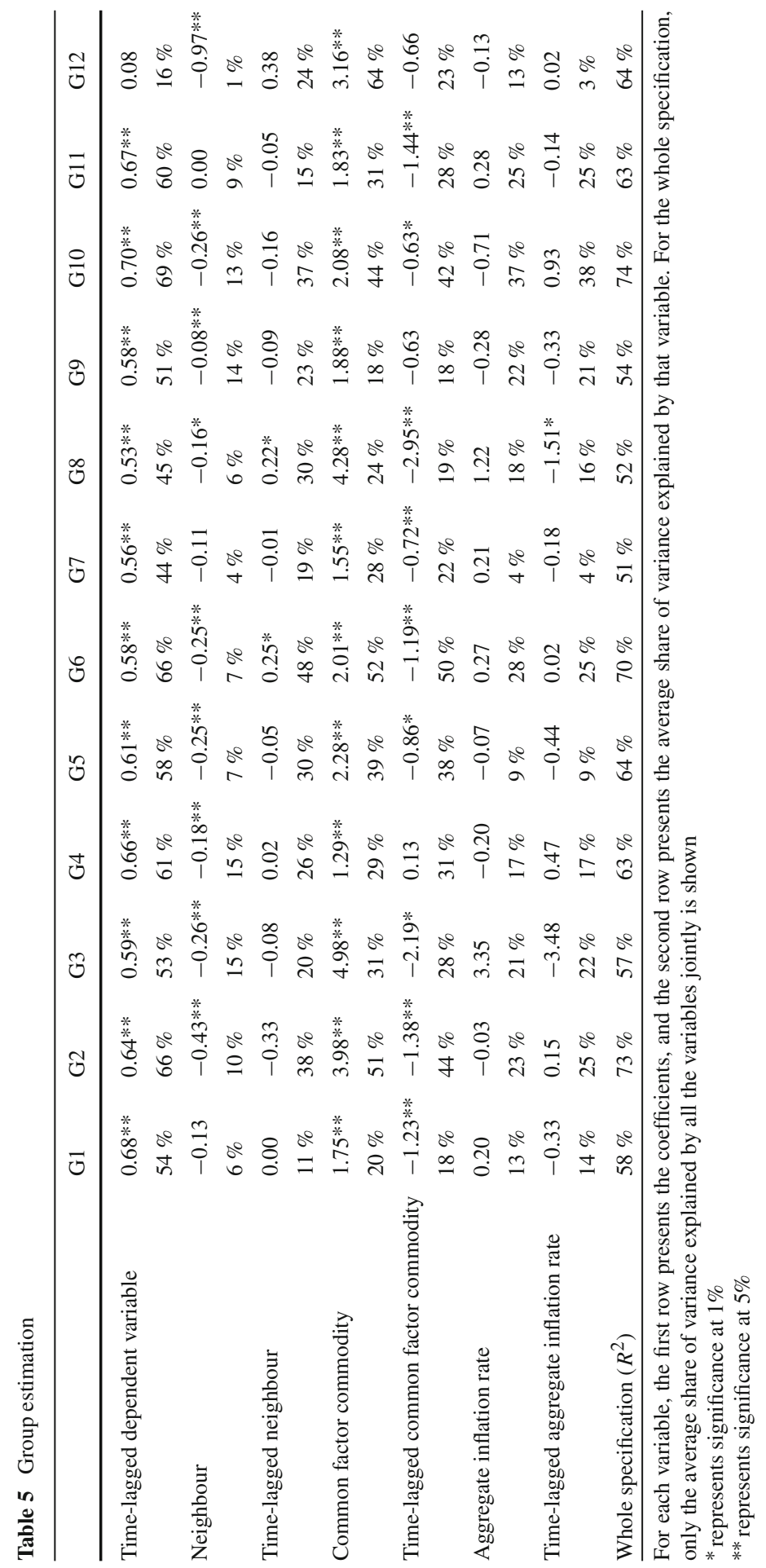


conduct an optimal monetary policy. This is especially relevant for the Chilean case where the overall inflation rate is computed based only on prices in the capital (Santiago de Chile). In fact, we hope that this article constitutes an empirical justification to compute the Chilean inflation rate based also on prices in the different and heterogeneous geographical areas of the country.

Finally, it is important to understand why the relative importance of common macroeconomic shocks and of transport costs in the determination of regional inflation dynamics varies in different parts of the world. Starting from the cases of Chile studied in this article and of the Euro Area (Beck et al. 2009), the investigation of this issue for other countries is warranted to determine under which circumstances regional inflation dynamics is more dependent on macroeconomic shocks or on transport costs. It is also worthwhile to investigate whether the conclusions would be sensitive to the use of different modes of transport (air, sea or road transport). This analysis cannot be carried out for Chilean regions, but it would be possible for other data. The issue is certainly important because, while the impact of macroeconomic shocks can be influenced by monetary policy, the impact of transport costs can be influenced by transport technology. Hence, knowledge of their relative role may carry policy implications.

Acknowledgments J. D. Tena acknowledges financial support from the British Academy under the Visiting Scholars Programme while working on this article. The authors are also grateful to the anonymous referees whose comments have greatly contributed towards improving the article. The usual disclaimer applies.

\section{Appendix 1: First-order conditions in the theoretical model}

The equilibrium (in log-linear form) is represented by the following system of equations:

$$
\begin{gathered}
\hat{p}_{t}=n \hat{p}_{t}(c)+(1-n)\left[\hat{t}_{t}+\hat{p}_{t}^{*}(p)\right] \\
\hat{p}_{t}^{*}=n\left[\hat{p}_{t}(c)+\hat{t}_{t}\right]+(1-n) \hat{p}_{t}^{*}(p) \\
\hat{p}_{t}-\hat{p}_{t}^{*}=-n \hat{t}_{1}+(1-n) \hat{t}_{t} \\
\hat{y}_{t}=\theta\left[\hat{p}_{t}-\hat{p}_{t}(c)\right]+\hat{c}_{t}^{w} \\
\hat{y}_{t}^{*}=\theta\left[\hat{p}_{t}^{*}-\hat{p}_{t}^{*}(p)\right]+\hat{c}_{t}^{w} \\
\hat{c}_{t+1}=\hat{c}_{t}+\frac{\delta}{1 \frac{1}{\delta}} \hat{r}_{t+1} \\
\hat{c}_{t+1}^{*}=\hat{c}_{t}^{*}+\frac{\hat{r}_{t+1}}{1+\delta} \hat{p}_{t+1}-\hat{p}_{t} \\
\hat{m}_{t}-\hat{p}_{t}=\hat{c}_{t}-\frac{r_{t+1}}{1+\delta}-\frac{\hat{p}^{*} \delta}{\delta} \\
\hat{m}_{t}-\hat{p}_{t}^{*}=\hat{c}_{t}^{*}-\frac{r_{t+1}}{1+\delta}-\frac{\hat{p}_{t+1}^{*}}{\delta} \\
\bar{c}=\delta \bar{b}+\bar{p}(c)+\bar{y}-\bar{p} \\
\bar{c}^{*}=-\left(\frac{n}{1-n}\right) \delta \bar{b}+\bar{p}^{*}(c)+\bar{y}^{*}-\bar{p}^{*}
\end{gathered}
$$


where for each variable $x_{t}$, we define $\hat{x}_{t} \equiv d x_{t} / x_{0}$ and $\bar{x}$ corresponds to its value in equilibrium.

Equations (8.1) and (8.2) are the log-linear form of the central and peripheral price indexes under the assumption of asymmetry among each region's producer, and the relationships between prices in the two regions are sketched in Eq. (8.3). The log-linear form for the demands of an individual good produced in the central and peripheral regions are described in Eqs. (2.14) and (2.15) in which we define world consumption as

$$
\hat{c}_{t}^{w}=n \hat{c}_{t}+(1+n) \hat{c}_{t}^{*}=n \hat{y}_{t}+(1+n) \hat{y}_{t}^{*}=\hat{y}_{t}^{w}
$$

Equations (8.4) to (8.9) express the first-order conditions from the maximization of the individual utility function, whereas the last two equations derive from the integration of the individual's period budget constraint over time and the imposition of the transversality condition.

\section{Appendix 2: Time series}

The time series considered in the analyses can be freely obtained from the Chilean National Statistical Institute at the following URL: http://www.ine.cl. The panel database consists of observations for 98 different items in 23 different Chilean cities on monthly basis for the period 2003:01-2006:09.

The cities and items in the sample are listed below:

Cities: Chillán, Copiapo, Quillota, Coihaique, Concepción, Linares, Iquique, Punta Arenas, Los Ángeles, Osorno, Rancagua, Arica, Los Andes, San Antonio, Valparaiso, Curicó, Puerto Montt, Talca, San Fernando, Valdivia, Temuco, Antofagasta, La Serena.

\section{Items}

Group 1: bread \& cereals - r1: Normal bread (kg), r2: Special bread (no package) (kg), r3: Rice (kg), r4: Flour (kg), r5: Oats (500 g), r6: Noodles No 5 (400 g), r7: Noodles $N^{\mathrm{o}} 87$ (400 g), r8: Spiral Noodles (400 g), r9: Quifaro Noodles (400 g), r10: Wafer biscuit (140 g), r11: Lemon biscuit (140 g), r12: Water biscuit (210 g), r13: Salted potatoes (230 g), r15: Pai (15 persons), r44: Cereal (box) (510 g) Group 2: fresh meat - r16: Meat (best quality) (kg), r17: Beef ribs (kg), r18: Rump, Cap and Tail Off (kg), r19: Filet (kg), r20: Sirloin Tip (kg), r21: Shank (kg), r22: Minced meat $10 \%$ fat $(\mathrm{kg}), \boldsymbol{r} 23$ : Pork chop $(\mathrm{kg}), \boldsymbol{r} 24$ : Pork rib cage (no seasoning) (kg), r25: Chicken (kg), r26: Chicken breast (kg), r27: Turkey breast $(\mathrm{kg})$

Group 3: fresh fish - r28: Fish (kg)

Group 4: canned \& processed meat \& fish - r29: Canned mackerel (425 g), r30: Canned tuna (184 g), r31: Canned sardines (125 g), r32: Ham (kg), r33: Culin bologna (kg), r34: Sausages (20 units), r35: Spicy sausages (kg), r36: Beef Paté (125 g), r50: Powered gelatine (160 g), r80: Chicken gravy cubes (8 units)

Group 5: fresh dairy products - r37: Mayonnaise (250 cc), r38: Eggs (12 units), r39: Milk (bag) (lt), r40: Milk (pack) (lt), r45: Salted butter (kg), r46: Cheese 
(kg), r47: Cream Cheese (kg), r48: Cheese (bag) (360 g), r49: Yogurt (175 g), r89: Ice cream (lt)

Group 6: preserved dairy products - r41: Powdered milk (1,6 kg), r42: Powdered milk (kg), r43: Sweetened condensed milk (400 g), r51: Powered caramel pudding (180 g), r82: Fortifier for milk (400 g)

Group 7: vegetable fats - r52: Vegetable oil(1t), r53: Sunflower oil(lt), r54: Salted Margarine (250g)

Group 8: fresh fruits \& vegetables - r55: Avocado ( $\mathrm{kg})$, r56: Organic tomato $(\mathrm{kg})$, r57: Normal tomato $(\mathrm{Kg})$, r58: Lemons (kg), r59: Apples (kg), r60: Oranges $(\mathrm{Kg})$, r61: Bananas (kg), r64: Potatoes (kg), r65: Garlics (3 units), r66: Onions (kg), r67: Lettuce (one), r68: White cabbage (one), r69: Carrots (bunch), r70: Pumpkin $(\mathrm{kg})$, r73: Green beans $(\mathrm{kg})$

Group 9: canned \& dried fruits \& vegetables - r14: Olives (300 g), r62: Canned peaches (590 g), r63: Canned peas $(310 \mathrm{~g}), \boldsymbol{r} 71$ : Lentils $5 \mathrm{~mm}(\mathrm{~kg}), \boldsymbol{r} 72$ : Beans (kg), r74: Tomato sauce (bottle) (250 g), r75: Tomato sauce (tetra) (215 g), r77: Marmalade (250 g), r79: Instantaneous soup (70 g)

Group 10: sugar \& salt - r76: Sugar (kg), r78: Salt (kg)

Group 11: beverages - r81: Coffee $(170 \mathrm{~g})$, r83: Tea $(250 \mathrm{~g})$, r84: Tea bags (20 units), r85: Bottled soft drink (2 lt), r86: Canned soft drink $(355 \mathrm{cc}), \boldsymbol{r 8 7}$ : Organic juice (lt), r88: Powder juice (45 g), r90: Wine (lt), r91: Sparkling mineral water (1,6 lt), r92: Bottled beer (1t), r93: Canned beer (355 cc), r94: Pisco especial 350 (750 cc), r95: Pisco especial 350 $(645 \mathrm{cc})$

Group 12: gasoline - r97: Gasoline 95 octanes (lt), r98: Gasoline 97 octanes (lt), r96: Gasoline 93 octanes (1t)

\section{Macroeconomic national factor}

The macroeconomic national factors were obtained by principal components from the following variables:

- Source: EcoWin. Production, Manufacturing, Index, 2002 = 100 (Ew:clp02005); Labour Cost, Real, total, Constant Prices, Index, 2006M1 = 100 (ew:clp10020); Inactivity, Economic inactive population, total (ew:clp09030); Chile, Money supply M3, CLP (ew:clp12005); Light Crude Futures 33-Pos, Nymex, Close (ew:com2431510); OPEC Reference Basket Price, Average (ew:com2121010).

- Source: Central Bank of Chile. Interbank loan rate (1 day); Exchange rate from the central bank of Chile.

\section{References}

Andrés J, Ortega E, Vallés J (2008) Competition and inflation differentials in EMU. J Econ Dyn Control 32(3):848-874

Altissimo F, Benigno P, Rodriguez-Palenzuela D (2005) Long-run determinants of inflation differentials in a Monetary Union. NBER WP 11473

Anselin L (1987) Spatial dependence and spatial heterogeneity: a closer look at alternative modeling approaches, Working paper, Department of Geography, University of California, Santa Barbara, CA

Anselin L (1988) Spatial econometrics, methods and models. Kluwer Academic, Boston 
Arbia G (2006) Spatial econometrics. Springer, Berlin

Beck G, Hubrich K, Marcellino M(2009) Regional inflation dynamics within and across Euro Area countries and a comparison with the US. Econ Policy 24(57):141-184

Beck G, Hubrich K, Marcellino M (2011) On the importance of sectoral and regional shocks for price-setting. CEPR Discussion Papers 8357, C.E.P.R. Discussion Papers

Beck N, Katz J (2004) Time-series-cross-section issues: dynamics. New York University, New York

Boivin J, Giannoni M, Mihov I (2009) Sticky prices and monetary policy: evidence from disaggregated US data. Am Econ Rev 99:350-384

Cecchetti S, Mark N, Sonora R (2002) Price index convergence among United States cities. Int Econ Rev 43:1081-1099

Drukker DM, Prucha IR, Raciborski R (2011a) Maximum-likelihood and generalized spatial two-stage least-squares estimators for a spatial-autoregressive model with spatial-autoregressive disturbances. Department of Economics, University of Maryland, Mimeo

Drukker DM, Prucha IR, Raciborski R (2011b) A command for estimating spatial-autoregressive models with spatial-autoregressive disturbances and additional endogenous variables. Department of Economics, University of Maryland, Mimeo

Fujita M, Krugman P (1995) When is the economy monocentric?: von Thunen and Chamberlin unified. Reg Sci Urban Econ 25(4):505-528

Fujita M, Krugman P, Venables A (1999) The spatial economy. Cities, regions and international trade. MIT Press, Cambridge

Hall AR (2005) Generalized method of moments. Oxford University Press, Oxford

Helpman E, Krugman P (1985) Market structure and foreign trade: increasing returns imperfect competition, and the international economy. MIT Press, Cambridge

Kelejian HH, Prucha IR (1998) A generalized spatial two stages least square procedure for estimating a spatial autoregressive model with autoregressive disturbances. J Real Estate Finance Econ 17(1):99-121

Kelejian HH, Prucha IR, Yuzefovich Y (2004) Instrumental variable estimation of a spatial autoregressive model with autoregressive disturbances: large and small sample results. In: LeSage JP, Pace RK (eds) Advances in econometrics: spatial and spatio-temporal econometrics. Elsevier, Oxford, pp 163-198

Kelejian HH, Prucha IR (2010) Specification and estimation of spatial autoregressive models with autoregressive and heteroscedastic disturbances. J Econom 157(1):53-67

Krugman P (1991) Increasing returns and economic geography. J Political Econ 99(3):483-499

Krugman P (1995) Innovation and agglomeration: two parables suggested by city-size distributions. Jpn World Econ 7(4):371-390

LeSage J (1999a) Spatial econometrics: the web book of regional science. Regional Research Institute, West Virginia University, Morgantown

LeSage J (1999b) The theory and practice of spatial econometrics. A manual to accompany the spatial econometrics toolbox. http://www.spatial-econometrics.com

Levin A, Lin Ch, James Chu Ch (2002) Unit root tests in panel data: asymptotic and finite-sample properties. J Econom 108:1-24

Mackoviak B, Moench E, Wiederholt M (2009) Sectoral price data and models of price setting. J Monet Econ 56:78-99

Obstfeld M, Rogoff K (1995) Exchange rate dynamics redux. J Political Econ 103:624-660

Parsley D, Wei S-J (1996) Convergence to the law of one price without trade barriers of currency fluctuations. Quart J Econ 111:1211-1236

Pesaran MH (2006) A simple panel unit root test in the presence of cross-section dependence. J Appl Econom 22(2):265-312

Piras G (2010) Sphet: spatial models with heteroskedastic innovations. R. J Stat Softw 35(1):1-21. http:// www.jstatsoft.org/v35/i01/

Samuelson P (1952) The transfer problem and transport costs: the terms of trade when impediments are absent. Econ J 62:278-304

Schumacher C, Breitung J (2008) Real-time forecasting of German GDP based on a large factor model with monthly and quarterly data. Int J Forecast 24:386-398

Stock J, Watson M (2002) Macroeconomic forecasting using diffusion indexes. J Business Econ Stat 20:147162

Tena JD, Espasa A, Pino G (2010) Forecasting Spanish inflation using the maximum disaggregation level by sectors and geographical areas. Int Reg Sci Rev 33:181-204 